\title{
Two-dimensional Pressure-Driven Nanorod-to-Nanowire Reactions in Langmuir Monolayers at Room Temperature
}

\author{
Somobrata Acharya and Shlomo Efrima*
}

Department of Chemistry and the Ilse Katz Center for Meso- and Nanoscale Science and Technology, Ben-Gurion University, Beer-Sheva, POB 653, Israel 84105

Supplemental Material:

The figure shows wires produced by coalescence of nanorods on a Langmuir trough at $45^{\circ} \mathrm{C}$ and a surface pressure of $50 \mathrm{mN} / \mathrm{m}$. It demonstrates the crystalline structure that is conserved across the joints between the rods. In fact, one hardly sees the joints, since they are so smooth. We can tell that they are there since the original rods are $4.5 \mathrm{~nm}$ long.

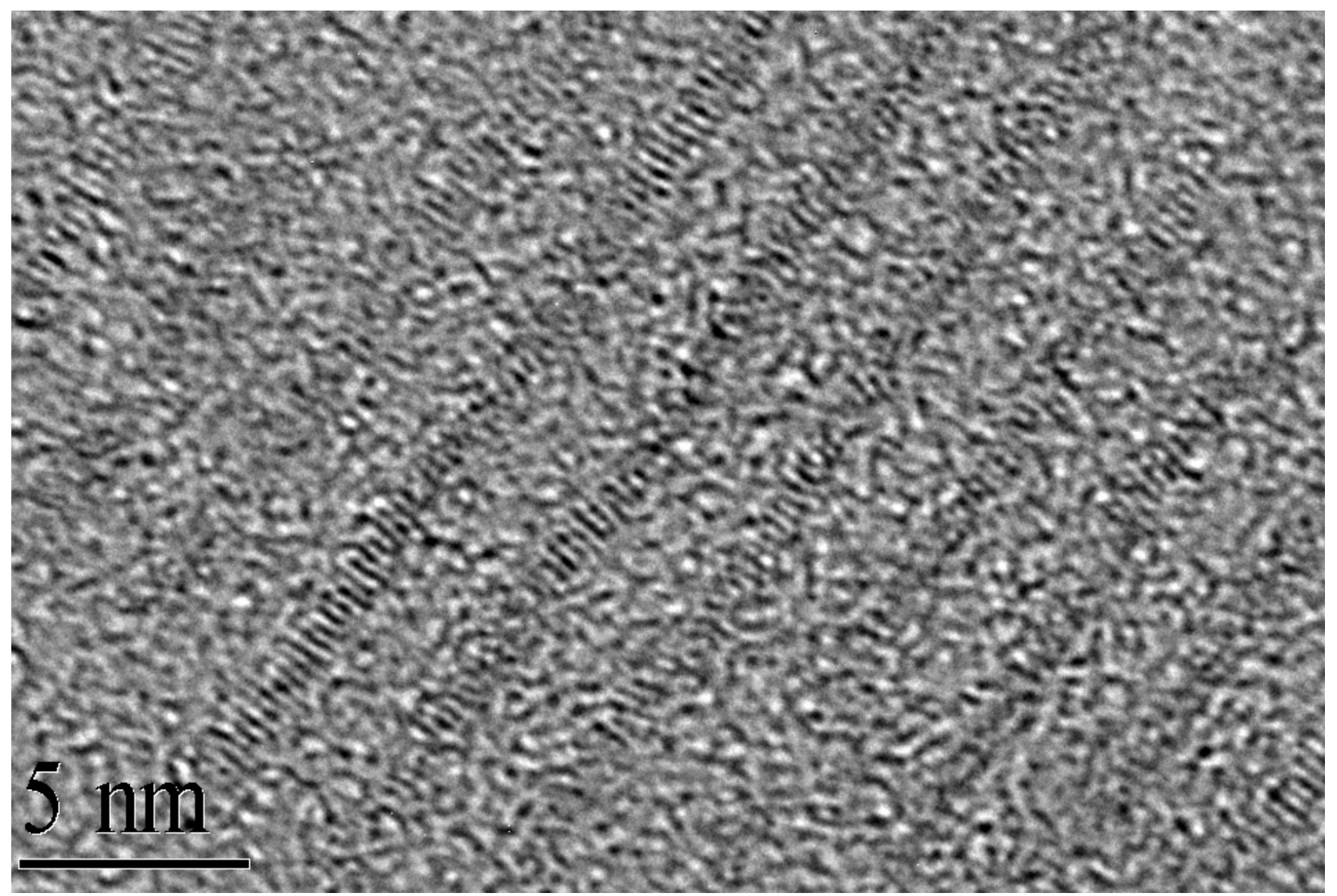

